\title{
Rational volcanic hazard forecasts and the use of volcanic alert levels
}

\author{
Paolo Papale(1)
}

\begin{abstract}
Volcanologists make hazard forecasts in order to contribute to volcanic risk assessments and decision-making, in areas where volcanic phenomena have the potential to impact societal assets. Present-day forecasts related to the potential occurrence of an eruption mostly take the form of alert levels, that are established by volcano scientists with the aim of communicating the state of a volcano and its possible short-term evolution. Here I analyse current alert level systems and their role in decision-making processes. I show that the use of such systems implies predictive capabilities not supported by corresponding levels of confidence in the knowledge of the volcano. Their use also implies an assumption of volcano scientist responsibility for decisions that goes beyond the expertise of the scientist, and which, in most countries, is not granted by a corresponding societal mandate. A rational volcanic hazard forecast system accepts instead the uncertain nature of volcanic processes and the consequent limited predictive capabilities; forecasts expressed as probabilities, or better as probability distributions, reflect a rational attitude by scientists and assure clear roles that reflect both expertise and societal mandate to any group involved in the management of a volcanic crisis. Exceptions where the use of volcanic alert levels may lead to efficient management are also discussed.
\end{abstract}

Keywords: Rational hazard forecasts, Volcanic crisis, Volcanic alert levels, Alert colour codes

\section{Introduction}

Any process that includes some randomness should be regarded as "uncertain" to some extent, and be treated in the context of statistical analysis. This is true for any aspect of human activities where forecasts are needed, and substantial gains and losses depend on such forecasts. Examples include financial forecasts regarding the trends of single stocks or the stock market, political forecasts regarding the stability and trends of individual nations or geographic areas, insurance forecasts regarding the potential losses and gains deriving from acceptance of given investment risks, weather forecasts, and many others including decisions we currently make in everyday life (e.g., Lipshitz and Strauss 1997; Lau and Redlawsk 2001; Levy 2015). In all such cases decisionmakers evaluate the costs and benefits associated with each possible action, which is usually carried out by considering both statistical trends and specific information regarding the case under evaluation.

Correspondence: paolo.papale@ingv.it

Istituto Nazionale di Geofisica e Vulcanologia, Sezione di Pisa, via Della Faggiola 32, 56126 Pisa, Italy

(c) The Author(s). 2017 Open Access This article is distributed under the terms of the Creative Commons Attribution 4.0 International License (http://creativecommons.org/licenses/by/4.0/), which permits unrestricted use, distribution, and reproduction in any medium, provided you give appropriate credit to the original author(s) and the source, provide a link to the Creative Commons license, and indicate if changes were made.
Volcanic processes are largely dominated by uncertainties. These are both epistemic, due to limited knowledge and understanding, and aleatoric or intrinsic, due to the high non-linearity of volcanic processes causing exceedingly large dependency on initial/boundary conditions (e.g., Marzocchi and Bebbington 2012). The fact that a large part of any volcanic system is not accessible to direct observation is a source of epistemic uncertainty and a great limit to predictive capabilities; however, no matter how deep we get into that system, or how sophisticated are our physical models, aleatoric uncertainties cannot be reduced, not even in principle, resulting in an intrinsic "aleatoric" or random character in volcanic processes. Both epistemic (reducible in principle), and aleatoric uncertainties significantly limit the capability of deterministic approaches to predict volcanic hazards; because uncertainties largely dominate, forecasts make use of statistics and probabilities.

Uncertainties in natural processes, as well as in many other fields of investigation or human activities, are difficult to deal with; our mind is not effective when statistical reasoning is required. On the contrary, humans instinctively search for cause-effect associations fulfilling

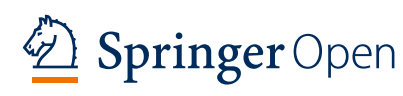


a need for "control" that is comforting in the relationships with the world around us. The Nobel Prize Daniel Kahneman (2011) associates intuition to a constant, instinctive scan of human brain in search for cause-effect relationships, identifying its origin in a powerful reward by natural selection: a being that is effective in recognizing causes beyond their visible effects, is advantaged in quickly escaping bad situations, as well as in efficiently taking advantage of positive conditions. Scanning the environment in search of cause-effect relationships yielded increased chances of survival, and natural selection has worked to transform that capability into a fundamental character of our automatic response to external stimuli: our intuitive approach.

That attitude is not bad at all; not only it has favoured us in the fight for survival, but it has produced a flourishing science based on cause-effect relationships that allows us to explore the world and the Universe. We are, with reason, immensely proud of discovering the laws of nature; at the same time we are not, and we will never be, able to predict the answer to an exceedingly large number of extremely relevant questions, including the followings: will I have a car accident today while driving to my office? Is my new enterprise going to make me rich or bankrupt? Will it rain on next April 6th after lunch? Is this volcano going to erupt in the next year? And many others.

Overcoming the intuitive cause-effect attitude and recognising that the world around us is much less predictable than we would like it to be, requires a rational effort that is not easy at all. Unpredictability is largely discomforting as it jeopardizes our sense of control on the world, making us feel defenceless. However, rational approaches that accept deterministic unpredictability in most situations around us, and account for the uncertain nature of the world, allow us to deal with the hard questions above, and for each of them, to make forecasts in a form appropriate to make rational decisions. In this paper I argue that the rational approach described here, besides being appropriate with respect to the complex nature of the world, leads to hazard forecasts that implicitly include a clear, unambiguous identification of the roles of volcano scientists, which are obviously bounded by their knowledge and expertise; whereas the intuitive approaches, unfortunately widespread in volcanology, lead to frequent, inevitable superposition of roles between volcano scientists and decision-makers.

In the following I consider the present-day situation with respect to short-term hazard forecasts, here referred to as the evaluation of the likelihood of a forthcoming eruption or other potentially hazardous events at a given volcano. Such evaluations are usually expressed in terms of alert levels (e.g., Fearnley et al. 2012), represented by a series (usually three to five, but they can be more) of discrete levels, determined by volcano scientists on the basis of their observations and expert knowledge, each one implicitly (or in some cases explicitly) associated with a different "likelihood", which, in turn, is sometimes tied to associated actions. The arguments that I develop here demonstrate that such alert level tables are dominantly developed and used through an 'intuitive approach', rather than through rational thinking that should drive scientific evaluations. I also argue that the use of alert level tables imbues scientists with an inappropriate role as decisionmakers. In contrast, rational volcanic hazard forecasts fully and explicitly account for the uncertain nature of both volcanic processes and the evolution of a volcanic system, thus maximizing the exploitation of diverse knowledge and expertise for societal benefits. I argue that rational volcanic hazard forecasts assure a clear, unambiguous distinction between volcano scientists and decision-makers, with the formers providing forecasts in the probabilistic form that is best suited for decision-making under uncertainty - the natural state characterizing any situation of volcanic risk.

A further clarification is needed here. It is a fact that the role of scientists in the management of natural risks varies substantially from country to country, reflecting different cultures and different societal and political contexts. One extreme case is represented by Indonesia, where volcano scientists are increasingly given the duty of recommending practical actions that directly impact the societies at risk, such as evacuation or relocation of human settlements. The overwhelming majority of countries, however, accepts the principle of separation of roles between the scientists and the decision-makers (e.g., Marzocchi et al. 2012), with the former providing expert evaluations, and the latter making decisions based on their respective political and societal mandates. That principle contributes to maximizing benefits from the effective cooperation of all participants, with each contributing based on their expertise, and with clear roles bounded by their respective responsibilities. Although I am aware of possible limitations in applying the arguments in this paper to all of the varied cultures and societies in our world, I do assume separation of roles between scientists and decision-makers as a guiding principle.

It is worth noting here that although the arguments presented are general, their relevance increases with increasing volcanic risk. Forecasting hazards is applied science: we make forecasts because of compelling social and economic risks associated with volcanic eruptions. It is reasonable to state that hazard forecasts are informed by risk evaluations; accordingly, it is also reasonable that the practices leading to hazard forecasts vary with the level of risk. In low risk situations those practices may demand less sophisticated evaluations and techniques: when the costs associated with mitigation actions, e.g., 
evacuation of the population at risk, are low, sophisticated analyses are not required since actions can be carried out at low cost following little warning. In contrast, high-risk situations like those involving urban areas and cities exposed to dangerous volcanic phenomena incur substantial costs regardless of whatever measure is taken (or not taken), thus requiring more refined, rational approaches involving clear, sound, transparent, auditable practices for both hazard forecasts and decision-making. High-risk urbanized areas are therefore the main target of the arguments presented here. The Conclusions section includes examples of high-risk situations demanding a rational approach like the one depicted here. It also includes examples of situations involving reasonable, low-cost, much less sophisticated mitigation actions, for which the application of VALS can be legitimate and effective.

In the following sections I examine current alert level systems and their use in communications from volcano observatories, and argue that the use of VALS entails evaluations that transcend volcano science to involve social and political aspects, forcing volcano scientists to overstep their expertise as well as their mandated societal role. I then introduce volcanic hazard forecasts based on probability estimates, that instead guarantee clear distinction between scientific evaluations made by scientists, and decisions for the benefit of society (made by political decision-makers). I conclude by proposing a rational decision-making procedure that ensures full appreciation of the uncertain nature of volcanic hazard estimates and maximizes the collaborative contributes of several experts and political decision-makers, while keeping clear separation of roles according to each participant's respective expertise and societal mandate.

\section{Alert levels}

Alert levels represent the most widespread practice worldwide to communicate the state of and provide short-term forecasts for any single volcano (e.g., Potter et al. 2014). Alert levels are usually defined by volcano observatories, and represent the "official" communication of volcano status by scientists to public officers, politicians, media, and society. Alert levels adopted by different countries or even different volcano observatories in the same country may differ significantly, both in their number of levels and in the definition of each individual level. In response to the growing interest and effective use of Volcanic Alert Level Systems (VALS), IAVCEI - the international association of volcanologists - has recently launched a "Volcanic Alert Level Working Group".

Probably the most common VALS include a scale of four levels associated with different colours (also referred to as the "colour scale of alerts"), as depicted in
Table 1. A similar four-level colour scale is used for communications by the Volcanic Ash Advisory Centres (VAAC) that inform civil aviation authorities on the potential presence of ash clouds along airplane routes worldwide.

VALS can be very effective as an immediate means of communication about the state of a volcano; they do a good job when the speed of information is crucial, e.g., in the case of VAAC operations cited above. VALS are also useful as a source of global or regional information at a basic level, e.g., by allowing a quick assessment of the number of volcanoes in a given area that are in a state of unrest or eruption, providing a qualitative evaluation of the overall threat from imminent or on-going volcanic eruptions in different areas. VALS have been proven effective for the basic communication of the "level of risk" (although not strictly appropriate) in developed as well as developing countries where volcano scientists are engaged in communicating an accurate perception of volcanic processes and their potential impacts on local populations.

There are obvious merits in VALS; these have led to their widespread use worldwide. However, the use of VALS may also have serious drawbacks that do not appear to have been fully considered yet. Those drawbacks deeply undermine the appropriateness of VALS as a means of communication by volcano scientists, and largely overcome benefits in many situations, as described below.

\section{VALS in science and decision-making}

The primary problem with VALS is that they discretize the status of a volcano in relation to the level of alert. It should be obvious that there is no equivalent discretization in the natural processes leading to volcanic hazards. In fact, such a discretization is by no means a scientific process: its value is exclusively in terms of specific actions (aimed at public safety) that can be tied to discrete alert levels or triggered by alert level changes. By deciding a change in the level of alert, what volcanologists actually do is to trigger actions. That is true regardless of whether or not practical actions are explicitly included in the alert level scale. In fact, it would be completely unreasonable for a decision-maker to take practical actions that impact on society and that are unrelated to alert level changes. Such a direct relationship between alert level changes and practical actions impacting society led Winson et al. (2014) to suggest to volcano observatories that they should engage in "less conservative decision-making - raising alert levels freely - so that mitigating action can be taken even when there is still considerable scientific uncertainty". Since discrete alert levels have a direct, immediate and exclusive value in terms of actions, volcanologists who decide alert 
Table 1 The four-level volcanic alert scale

\begin{tabular}{|c|c|}
\hline LEVEL & MEANING \\
\hline GREEN / NORMAL & Background \\
\hline YELLOW / ADVISORY & Above background \\
\hline ORANGE / WATCH & Escalation of signals \\
\hline RED / WARNING & Eruption imminent or in progress \\
\hline
\end{tabular}

level changes become de facto decision-makers. Examples of actions typically attached to alert levels, and their potential impacts on society, are reported in Table 2.

In a topical assessment of the practice of use of VALS by five volcano observatories located in the United States, Fearnley (2013) provided ground-based evidence of such shifting roles: "[...] the decision to move between alert levels is based upon a complex negotiation of perceived social and environmental risks." As it further emerges from that paper, decisions to change alert level transcend scientific understanding, involving social and political factors that volcano scientists from the observatories feel obliged to take into account. The summary in Table 2 shows substantial societal costs attached to alert level changes. Given the consequences of not raising alert levels enough, or in time, the concerns by volcano scientists appear more than justified. In consideration of the fact that volcanologists from other countries, e.g. The Philippines, and Indonesia as cited above, deliberatively include social and political aspects when assigning alert levels, Fearnley (2013) concludes that "A consideration of different approaches to negotiating uncertainty and risk that are deliberative would, therefore, be beneficial in volcanic hazard management insofar as these suggest effective practices for decision-making processes in assigning an alert level."

Although I understand the rationale behind that conclusion, my thesis is the exact opposite: in the context of the principle of separation of roles, scientists should base their evaluations exclusively on scientific knowledge, providing decision-makers with clear, unambiguous information that they can use to fulfil their societal and political mandates.
There is one relevant corollary to the statement above: providing decision-makers with clear, unambiguous information implies that scientists and decision-makers have a common language and reciprocal understanding, so that the information going through them can be effectively clear and unambiguous. In turn, that requires a long practice of cooperation that must be established well in advance of a crisis, when the social pressure is low and mutual exchange is mostly fruitful. The common practice of quick rotation in critical roles and responsibilities within the administration of many countries, especially developing ones, is a major hindrance to the possibility of establishing such fruitful relationships between scientists and decision-makers.

There is also a requirement implicit in the statement above, namely that when dealing with issues that have societal relevance, the contributions from each involved participant should be bounded by their corresponding societal mandate. When such boundaries are not guaranteed, assessments by volcanologists may be consciously or sub-consciously biased by their own social and political evaluations. Similarly, politicians may make decisions that are influenced by their own scientific beliefs. These assessments and decisions thus step over expertise and social mandate. In high-risk situations, that can translate into serious consequences for the safety and economy of the affected population and infrastructure.

It is worth noting here that the perceptions of U.S. volcano scientists reported in Fearnley (2013) do not necessarily reflect the USGS official policy, which requires volcanologists to base their evaluations on science and not on societal issues, while working closely with Civil Defense authorities to support and inform them in the

Table 2 Possible actions, and their potential impacts, commonly attached to alert levels

\begin{tabular}{|c|c|}
\hline LEVEL & $\begin{array}{c}\text { ACTIONS } \\
\text { and their potential impacts } \\
\text { ORDINARY MANAGEMENT }\end{array}$ \\
\hline GREEN & $\begin{array}{c}\text { LIMIT ACCESS, INCREASE SOCIAL AND POLITICAL ATTENTION } \\
\text { Tourism industry affected. Decreased property values. }\end{array}$ \\
\hline YELLOW & $\begin{array}{c}\text { CLOSE ACCESS. REDUCE/CLOSE SENSIBLE SOCIAL/PRODUCTIVE ACTIVITIES } \\
\text { Relevant social impact, social acceptance required. Economic impacts, possible } \\
\text { negative cascading effects on enterprises. Political risks. }\end{array}$ \\
\hline ORANGE & $\begin{array}{c}\text { SHUT DOWN OF ACTIVITIES. PARTIAL OR TOTAL EVACUATION } \\
\text { Enormous social and economic impacts. Loss of jobs and properties, people } \\
\text { relocation. Social costs for evacuation/relocation/etc. Closure of productive } \\
\text { activities, large negative cascading effects on enterpreunership. High political risks. }\end{array}$ \\
\hline RED
\end{tabular}


preparation of their response plans (J. Pallister, personal communication). Similar policies exist in many other nations. My point here is that in spite of the official policies, the practice by volcano observatories of using VALS in their communications puts volcano scientists in a position in which socially based elements inevitably creep into decisions on alert level changes.

The situation in the US is not dissimilar to that in other countries, where volcano scientists are often involved in evaluations that transcend their expertise. In Italy the decisions for volcano alert level changes are formally made by the national Department of Civil Protection (DPC), which is the main decision-making body in relation to all natural risks; volcano scientists from the observatories contribute by informing the DPC of their observations, records, and expert evaluations, but do not take part in decisions related to alert level changes. However, the decisions by the DPC are usually made under advice from a commission of appointed scientists, called the "Grandi Rischi" (Large Risks) Commission, that sadly became famous for the legal trial that followed the L'Aquila earthquake, Central Italy, in April 2009 (e.g., Nosengo 2011; Cartlidge 2011; Bretton et al. 2015). Although the formal decision on any alert level change is made by the DPC, the scientists in the Commission, when providing their high-level expert advice, are likely to find themselves, as reported by the US scientists in Fearnley (2013), confronted with the "complex negotiation of perceived social and environmental risks". In other words, they find themselves engaged in decisions that transcend their scientific expertise and must account for the social, political and economic complexities of the societies at risk, with all the consequences that Table 2 illustrates, especially when those decisions impact on urbanized areas.

The situation in Japan is even more extreme. Here the duty of releasing volcanic alert levels is assigned to the Japan Meteorological Agency (JMA). Volcanic alerts are organized in a scale of five levels that are explicitly "based on the target area and action to be taken" (http://www.data.jma.go.jp/svd/vois/data/tokyo/STOCK/kaisetsu/English/level.html). According to Fearnley (2013): "In sharp contrast [note: with US and New Zealand VALS], the Japanese VALS addresses the measures to be taken by specifying areas of danger, indicating extent of evacuation, and outlining the expected volcanic activity." In other words, Japanese scientists at JMA are directly assigned the duty of deciding on actions impacting the society, as such actions are explicitly and intimately linked to VALS, the decisions about which rest with JMA.

\section{Scientific knowledge, and how it is communicated} Saying that scientists should base their evaluations exclusively on scientific knowledge represents by itself a negation of the use of VALS by volcano scientists. Because there is no effective value in alert levels other than the actions that are attached to them or are triggered by them, alert levels should not be an element under consideration by scientists, neither when developing scientific knowledge nor when communicating it. Further considerations emerge when considering the effective knowledge upon which decisions on alert level changes are currently based at volcano observatories. Table 3 reports some definitions attached to elements that are diagnostic for alert level changes, as they are reported in the VALS in use by volcano observatories throughout the world.

Such elements are a mix of observations ("signs of...", "elevated", etc.), evaluations ("background level", "unstable", "increased likelihood"), and predictions ("imminent"). What is most relevant here, however, is that all of those elements are described in purely qualitative terms, leaving ambiguity on when an observed change is just an oscillation around the current conditions or it is "slight" or "moderate" enough, "intense" or "obvious" enough, etc. to determine an alert level change, thus providing volcanologists full discretion to decide whether or not to change the alert level. Under such conditions the worries about societal consequences, expressed by US volcanologists in Fearnley's survey referenced above, appear more than justified: decisions directly impacting society are not only inappropriately assigned to scientists, but have to be made within a framework that is discretionary and vague, leaving scientists alone to deal with the consequences of their decisions and the responsibilities inherent in those decisions.

A more quantitative basis to inform alert level changes and communicate with stakeholders has been recently developed in New Zealand (Potter et al. 2015), and consists of a Volcanic Unrest Index (VUI) varying from 0 to 4 , based on the overcoming of thresholds, or fulfilment of specific conditions, related to ten parameters grouped into seismicity, deformation, and geothermal/degassing. According to the authors, VUI "is not a volcanic eruption forecasting tool", although it is said to be developed "to assist with the effective communication of volcanic unrest to end users". Further discussion points to the difficulty in the definition of "background" and "unrest" states in VALS, outside a quantitative framework that the VUI provides: for example, a VUI equal to or greater than 2 is said to satisfy the definition of "unrest". No further relationships are provided between VUI 3 ("moderate unrest") and 4 ("heightened unrest") and higher VALs. Since New Zealand adopts a six-level VALS, with the first three levels ranging from "no volcanic unrest" to "moderate to heightened volcanic unrest" (Potter et al. 2014), VUI appears to expand, in practice, the first three levels into five, adding a quantified definition to each of them. 
Table 3 Descriptions of observations diagnostic for alert level change

\begin{tabular}{|c|c|}
\hline LEVEL & DIAGNOSTIC ELEMENTS \\
\hline GREEN & "Activity at typical background level" \\
\hline YELLOW & "signs of elevated unrest"; "increasing activity of..."; "the process is unstable"; \\
"slight (low, moderate) increase in..."
\end{tabular}

Although the relationships between VUI and VALs remain (purposely, I understand) unclear, VUI has the evident merit to largely overcome the vagueness and ambiguity of current VAL definitions. It does not, however, differ from VALs in discretizing the volcano state; it also adds an explicit deterministic element in the assignment of a volcano "status" linked directly to observations and records but with no associated uncertainty.

\section{Rational volcanic hazard forecasts}

The situation emerging from the above picture is that although uncertainties are an element under increasing consideration when forecasting the behaviour of a volcano - the use of intuitive-based VALS communicates undue confidence in the capability to discern the relevance of on-going volcanic processes and anticipate the future outcomes. It sends the message that, regardless of whether or not diagnostic observations are quantified in advance, the scientists will be able to determine the state of the volcano and the level of the corresponding alert, and ultimately, what's going on beneath the volcano. Obviously, I am not saying here that the scientists truly think that; they are more aware than anyone else of the complexities of volcanic processes and of the strengths as well as limitations of their understanding. What I mean is that the use of VALS by scientists, together with the way that scientists define them, communicates confidence in a deterministic capability to recognise and anticipate the behaviour of the volcano, rather than a full appreciation of the uncertain nature of volcanic processes and forecasts. This reflects an intuitive approach, as outlined in the Introductory section.

A rational attitude in forecasting volcanic hazards should be respectful of the distinct roles of the various actors involved in the management of volcanic crises, and fully acknowledge uncertainty as a fundamental condition upon which forecasts are based. The first part of this statement has been discussed above, and requires that volcano scientists abandon VALS as a means of evaluation and communication. The second part, discussed below, requires the use of statistics and probabilities as the major means of forecasting and communicating volcanic hazards. Together, these approaches provide the basis for a rational global system to manage volcanic crises.
Statistics and probabilities have played a role in volcanology for decades, and the number of published papers in this genre has been continuously increasing. A differentiation between frequency-based and Bayesian (or subjective) probability is relevant in volcanology as well as in any other field (economy, finance, politics, etc.) where uncertainties dominate the evaluations (e.g., Marzocchi and Jordan 2014). Whilst the former identifies the probability of an outcome with the frequency of occurrence of that outcome in a sufficiently large number of samples, the latter reflects the degree of belief in a given outcome, quantified from an a-priori estimate which is progressively adjusted as long as new information is added. Instead of estimating simple probabilities, the Bayesian approach leads to the quantification of probability density functions, or probabilities with associated uncertainties. Quite often the a-priori estimate (or the likelihood function used to modify that estimate) is obtained from observed frequencies, e.g., the frequency of the considered outcome in the available samples or in heterogeneous samples assumed to approximate the case under consideration, creating a bridge between frequencybased and Bayesian approaches.

The enormous success of the Bayesian approach reflects its capability to i) deal with highly uncertain situations with poor or no associated statistics, ii) take into account heterogeneous information from basically any kind of source including personal experience and belief, and iii) account in a formal way for the uncertainties deriving from the uncertain information available. Those characteristics are particularly valuable in volcanology, as the historical records are typically far from providing statistically robust information, and potentially useful knowledge comes from highly heterogeneous sources. Bayesian approaches are often used in conjunction with Event Trees (e.g., Newhall and Hoblitt 2002; Marzocchi et al. 2004, 2008; Newhall and Pallister 2015, and references therein), that represent the complex ramification of possible outcomes, each one quantified as a probability distribution which is allowed to evolve as long as new information is added (e.g., when new observations are available). To-date, Bayesian approaches have been employed in a large number of situations in volcanology, including forecasts of volcanic hazards over the shortterm (Aspinall et al. 2003, 2006; Marzocchi et al. 2008; 
Oliveros et al. 2008; Lindsay et al. 2010; Brancato et al. 2011, 2012; Bell and Kilburn 2012; Marzocchi and Bebbington 2012; Sandri et al. 2009, 2012; Selva et al. 2012, 2014; Garcia-Aristizabal et al. 2013; Anderson and Segall 2013; Rouwet et al. 2014; Aspinall and Woo 2014; Sobradelo et al. 2015; Boue et al. 2015; Tonini et al. 2016; Bartolini et al. 2016) as well as over the long-term (Martin et al. 2004; Baxter et al. 2008; Neri et al. 2008; Orsi et al. 2009; Marzocchi et al. 2008, 2010; Sobradelo and Martì 2010; Passarelli et al. 2010a, b; Selva et al. 2012; Marzocchi and Bebbington 2012; Sandri et al. 2012, 2014, 2016; Bebbington 2014; Becerril et al. 2014; Bartolini et al. 2014; Sheldrake 2014; Thompson et al. 2015; Bevilacqua et al. 2015; Tonini et al. 2015). Marzocchi et al. (2012) and Selva et al. (2012, 2015) review major challenges in the scientific management of volcanic crises, and illustrate a general quantitative procedure based on probability estimates, which by analogy to approaches in seismology (Jordan et al. 2011) is defined by the authors as "operational eruption forecasting". Here, I do not review the methods and their technical aspects; rather, I focus on the value of rational hazard forecasts, that account for both epistemic and aleatoric uncertainties that dominate in the natural processes involved in volcanic systems; and I outline a recommended best practice approach to dealing with volcanic hazards and risks, with reference to short-term forecasts.

The resistance to adopt probabilistic approaches when dealing with volcanic hazard forecasts has multiple origins. Perhaps the most deeply rooted opposition stems from the psychological refusal to accept a limit in the human capability to predict the evolution of a mechanistic system, no matter how complex it is. In fact, strictly speaking we are able to make predictions only under idealized conditions that do not exist in nature. In practice, however, we can approximate future outcomes to a satisfactory degree and call them predictions. That capability has driven the technological developments we know: we call it a prediction if our equations anticipate the trajectory of a satellite with a $1 \mathrm{~m}$ approximation, or the quantity of fuel necessary to send a rocket to the moon with a $1 \%$ error. What we call predictions are actually satisfactory approximations that are only possible when dealing with relatively simple systems under controlled conditions. With more complex systems, our predictive capabilities are sorely tried. The atmosphere is such a complex system, although we are still able to forecast weather: we observe and measure the atmosphere from below, from inside, and from above, twenty-four hours a day, through a huge number of multi-parametric instruments that produce enormous datasets and a continuous, detailed picture of its evolution at multiple scales, allowing continuous testing and refinement of increasingly sophisticated models. Still, the predictions are uncertain and expressed as probabilities, and their confidence is limited to a few days. Because the predictions have significant uncertainty, they are termed "forecasts". Volcanic systems are at least as complex as the atmosphere, with the difference that our direct monitoring of them is not even comparable. We know little of the internal and underground conditions at active volcanoes, other than the rough inferences that we make by observing and mapping extinct, ancient, eroded volcanoes or that we extract from geophysical, geochemical and petrologic information, which itself has large uncertainties. Our view of active underground magmatic systems, and their relationships with the surrounding rocks, is basically speculation, as we do not directly observe them (with the negligible exception of geothermal drilling at the Krafla caldera, in Iceland, that accidentally encountered magma, Pàlsson et al. 2014; and of scientific drilling into the surficial Kilauea Iki lava lake, Heltz 1980, 1987). It may be discomforting, but it is not surprising that our attempts to predict the evolution of volcanic systems are destined to take the form of exceedingly uncertain approximations; and that our probabilistic forecasts are affected or dominated by substantial uncertainties.

Besides the reasons reported above, there is also a technical difficulty limiting the widespread use of probabilistic forecasts in volcanic hazard evaluations. In fact, the vast majority of volcano observatories do not include experts in statistics and probability, because these disciplines have only recently begun to complement the multi-disciplinary approach that characterizes the science of volcanoes and its applications. As was the case with other fields of investigation, e.g., fluid geochemistry, satellite data analysis, and computational thermo-fluid dynamics, that have been increasingly contributing to volcanic hazard forecasts and scenario evaluation, there is no doubt that probabilistic analyses will increase in relevance for and be more present in volcano observatories, as well as at nearby cooperating Universities and research centers. To-date, computational tools and manuals can be freely downloaded from a number of sites, e.g., https://vhub.org/resources/betunrest for Bayesian Event Tree analysis for both magmatic and nonmagmatic unrest phases (Marzocchi et al., 2008; Rouwet et al., 2014; Tonini et al., 2016), or https://www.norsys.com/download.html for Bayesian Belief Network analysis, the latter having been applied to urgent decision support during the unrest at Santorini in 2011-2012 (Aspinall and Woo, 2014).

Ideally, forecasts by volcano scientists referring to the possible occurrence of potentially hazardous phenomena, should represent the probability distribution for each outcome of potential interest, and the evolution of such distributions in time as new observations and records are produced. An example is given in Selva et al. 
(2012), where computed probabilities refer to the branches of a simple event tree with nodes corresponding to "unrest" vs. "no unrest"; and in the former case, to unrest due to "magmatic" movements as compared to unrest exclusively related to the activity of the geothermal system; and again, in the former case, to magmatic movements expected to culminate, or not to culminate, into an "eruption". The evolution in time of the probabilities for the "magmatic" unrest and "eruption" nodes, shown in Fig. 1, refers to an application during a volcanic crisis exercise at Campi Flegrei, held in February 2014 (Papale, De Natale et al. 2014).

The forecasts in Fig. 1 represent purely scientific evaluations by volcano scientists, in a rational approach that accounts for scientific knowledge as well as for the uncertainties accompanying that knowledge. Such forecasts require engagement of volcano scientists in only the scientific aspects of volcanic crises; they do not imply any decision by scientists on when new actions should be carried out, as it is the case with alert level changes; therefore, they do not bring about any of the discomforts related to the perceived necessity to balance scientific evaluations with their social consequences. On the contrary, probabilistic forecasts fulfil the hazard-risk separation principle according to which "authoritative scientific information [...] should be developed independently of its applications to risk assessment and mitigation" (Jordan et al. 2014). Probabilistic forecasts also fulfil the principle of separation of roles between scientists and decision-makers, advocated in the Introduction above: the social role of scientists requires the highest efforts in making scientific knowledge available for societal benefits, within the boundaries determined by their expertise and socio-political mandate that (at least in most countries) does not include making decisions for society. At the same time, probabilistic forecasts are in a form most suited to provide decision-makers with the realistic picture for their subsequent decisions. I stress that making decisions for society is always a political action; the meaning of politics is in fact making decisions and implementing actions for societal benefit. Decisionmaking, therefore, strictly requires a specific mandate from society. I add that making decisions related to volcanic (and in general other) risks requires far more than just volcano science. The aim of this paper is to discuss the limits and dangers embedded in the current use of volcanic alert levels, and the rational approach rooted in probabilities and uncertainties. However, putting decisionmaking in this same context helps understand the overall advantages of removing volcano scientists from the burden of decisions that go beyond their expertise and social mandate.

\section{Making decisions}

There is an immense literature on decision-making: a search in the ISI web of science with "decision-making" in the title yields about 45,000 entries, growing to more than 280,000 if searched as a topic. A search in Amazon reveals more than 5700 books with "decision-making" in their title. Decision-making is clearly a topical issue in virtually any field of human activities, where decisions must be made and actions taken, albeit with limited knowledge and under uncertain conditions, i.e. the 'normal' situation. The theories developed aim at providing a

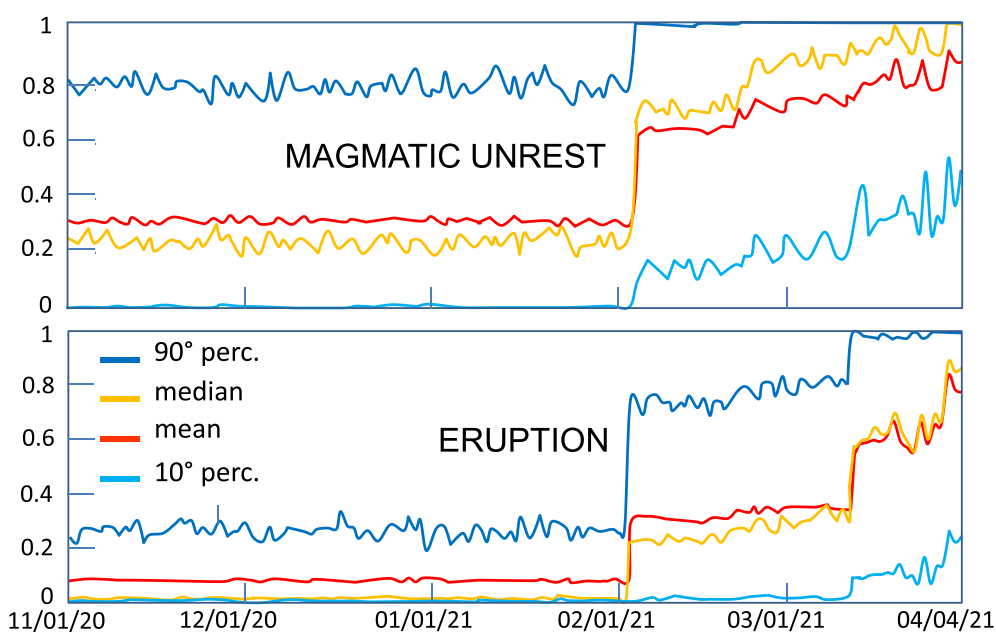

Fig. 1 Time evolution of the day-by-day probability associated with the nodes "magmatic unrest", and "eruption" of the event tree in Selva et al. (2012) computed for the last five months covered during a volcanic crisis exercise at Campi Flegrei. The exercise, conducted as part of the EU/ FP7 VUELCO project, was a blind test of the response of the scientific community to observations and records generated by a group simulating the volcano; and covered the period from February 2014 (time of the exercise) to 4 April 2021. The "unrest" node, not shown, would display a constant value of 1 for all lines in the panels and for the entire period in the figure. In the "eruption" panel, probabilities refer to a one-week time period. Computations: courtesy of L. Sandri, INGV 
rational framework within which to construct optimal decisions, where the word "optimal" refers to a balance between the pro's and con's of decisions being made. Such an optimal balance is usually identified through a "cost/benefit" analysis, where the costs are the con's, and the benefits are the pro's associated with a given decision. While the required mathematics can be variably complex, depending on the elements accounted for in the theoretical approach, the greatest difficulties are usually associated with the numerical values to assign to the relevant variables. That is a consequence of both the afore-mentioned uncertainties, and the fact that some of the variables to be accounted for may be difficult to quantify, e.g., the value of human life, the political consequences of unpopular decisions, and many others.

The literature on decision-making in volcano-related problems is relatively recent. In their pioneering work on cost/benefit analysis applied to volcanic risks, Marzocchi and Woo $(2007,2009)$ analyse the evacuation of an area at risk, and conclude that such a decision is justified when the probability of eruption occurrence overcomes a critical threshold given by the ratio between the costs associated with the evacuation, and the losses associated with no evacuation (including loss of lives) in the event the eruption occurs. More recently, the approach has been further developed by Bebbington and Zitikis (2016) to place it into a time-dependent framework which considers the time windows between effective changes in the eruption probability, the call of an evacuation and its completion, further evolution (either increasing or decreasing) in eruption probabilities, the actual eruption occurrence, and citizens' dislocation and their return to the affected areas. In a retrospective application to the 1631 sub-Plinian eruption of Vesuvius, they found that the eruption probability value justifying the evacuation call turns out to be $13 \%$ lower than for the "static" approach by Marzocchi and Woo (2009). Translated into the reconstructed time evolution of the eruption probability, that difference would have anticipated an evacuation call by six days. It is however highlighted that in a forward application, such as during a real crisis, the large uncertainty associated with the parameter expressing the time to eruption would translate into significant uncertainty in the optimum time for evacuation.

Cost/benefit analyses provide decision-makers with a solid baseline for making decisions, and a robust theoretical framework to justify those decisions; they also allow the effects of decisions to be translated into values, for example by providing the value for human lives corresponding to the time and conditions under which decisions are made; and to translate uncertainties into acceptable time windows for specific actions. Although the applications referred to above take into consideration the last and most critical decision related to an evacuation call, similar analyses may be conducted in principle in order to inform other relevant decisions during a volcanic crisis; e.g., with reference to Table 2, when to limit/close access to tourist areas and certain infrastructures; when to reduce or shut down sensitive activities (e.g. reduce/shut down blast furnaces operations, decrease the petrol/gas stocks in areas potentially subject to pyroclastic flows), and so on. It should be clear, in fact, that a progressive worsening of a volcanic crisis with the potential to impact heavily urbanized areas cannot be faced by just suddenly moving from "no action" to "evacuation"; rather, an effective management plan should guarantee that the evacuation time is progressively approached so that when the evacuation is called, the city is ready.

It is easy and immediate to see, in such a picture, where volcano scientists contribute: they provide their best scientific knowledge to estimate probabilities and reduce uncertainties related to expected volcanic phenomena, thus helping to inform both cost/benefit analyses, as well as political decision-makers who have the social and political mandate to make decisions and implement actions for societal benefit. Based on robust evaluations of probabilities (and their associated uncertainties) by volcano scientists, and on the complex body of information provided by volcanologists as well as by many other relevant experts (and eventually including cost/benefit analyses), decision-makers can add their political, social, and other perspectives to define critical probability (or cost/benefit ratio, or others) thresholds, "Alert Levels", in fact, that they may use as a trigger for implementing specific actions. In such a framework, volcano scientists do not define the thresholds, nor do they get involved in any evaluation of if and when to change an alert level and thus trigger actions. Provided that it is up to decision-makers to decide, the use of such VALS, fully informed by scientists but entirely defined by decision-makers, may be justified as it is consistent with the respective expertise and mandates of the various actors involved. In such a framework, volcano scientists provide just one element - albeit an extremely relevant one - in a very complex decision-making process that requires several complementary contributions, as well as constant and open cooperation between the many different experts providing information and advice to support those civil authorities in charge of making decisions that impact on society. Figure 2 exemplifies many of the necessary contributions, as well as the required constant, twoway interaction between scientists and decision-makers.

The scheme in Fig. 2 is necessarily a simplification of much more effective relationships between scientists and decision-makers required in the management of a volcanic crisis. Particularly, evaluations and deliverables produced by scientists (left group in Fig. 2) should be 


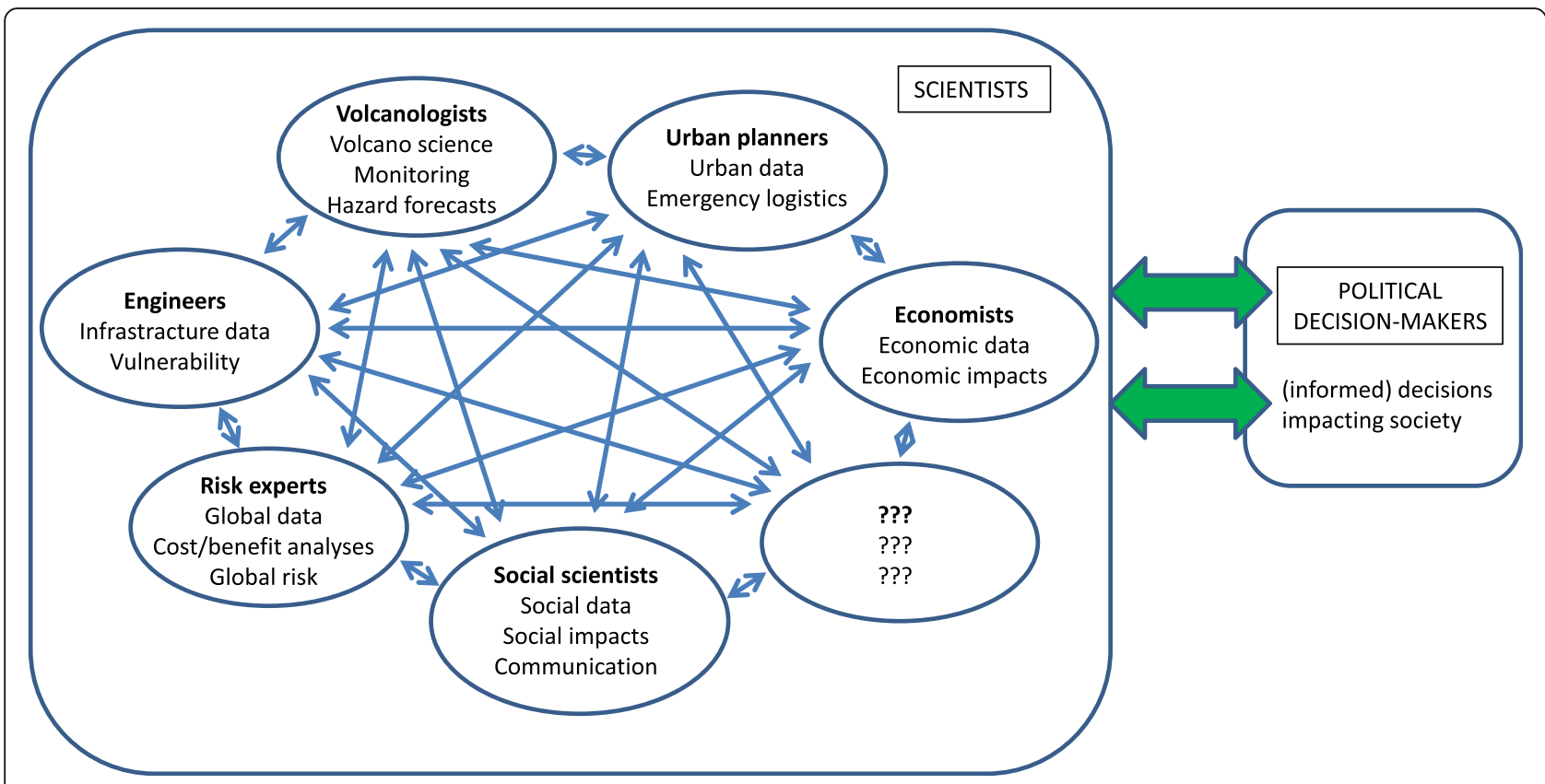

Fig. 2 Sketch of the complementary contributions required to inform decision-makers. The double arrows indicate two-way exchange occurring at all levels, among scientists (left group, blue arrows) and between scientists and decision-makers (right group, green arrows). Decisions are informed by science (left) and made by decision-makers (right), involving a constant process of interaction and exchange, definition of common language, and reciprocal understanding and trust

accompanied by meetings, presentations, and additional material further explaining the overall picture, the current conditions, and the potential scenarios. As outlined in Potter et al. (2014), decision-makers need to know what may happen next (they would like to know what is going to happen next, but such deterministic knowledge is not accessible), which requires much more than just numbers and graphics; rather, it requires an established practice of communication, reciprocal understanding, and trust as already pointed out above, that cannot be put in place just during a crisis. With that purpose, volcano scientists in many countries, e.g., the US, Italy, and many others, including several developing countries, are constantly engaged with Civil Defence authorities in fruitful dialogue, cooperation and exchange that create the basic conditions necessary for the full development of a rational approach such as is depicted in Fig. 2.

Once again, I stress that while scientists have the social duty of providing their best knowledge to inform decision-makers, decisions impacting society are by definition a political action, and can only be made under a clear mandate from society. Fig. 2 shows that decisions do not immediately follow from any of the evaluations by scientists, no matter how advanced such evaluations may be. Instead, decisions descend from a social and political mandate; they must be informed by science (not just volcano science, Fig. 2), and may include other factors which transcend purely science-based evaluations and are only managed by political decision-makers.

\section{Conclusions}

Volcanic alert level systems (VALS) of widespread use at volcano observatories result in a mix up of scientific assessments and social, economic and environmental evaluations that prevent clear, unambiguous communication. In addition, they exceed the social role of volcano scientists in most modern societies. The principle of separation of responsibilities between scientists and decisionmakers requires instead that scientific evaluations be reached without any element external to scientific understanding, and that decisions impacting society be made under clear mandate by society itself. Rational hazard forecasts should fully recognize the large, indeed dominant role of uncertainties in volcanic processes, and be therefore expressed through probabilities. Besides reflecting the complex nature of volcanic processes and our limited capability to anticipate their evolution, such a rational attitude implies that volcano science be the only focus of volcanologists during a volcanic crisis. Although protecting volcanologists against legal issues related to their conduct during a crisis is not among the arguments in this paper, it should be noted that as a consequence of rational volcanic hazard forecasts, volcanologists are released from the inappropriate duty of making 
decisions impacting society. Making such decisions is by definition a political action; volcanologists, as well as other experts from different fields of science, contribute by informing political decision-makers through clear, unambiguous, effective language and communication, enabling decision-makers to execute the roles and duties that are within their societal mandate.

It should be stressed once again that the present arguments and conclusions become increasingly relevant with increasing volcanic risk, as well as with increased social, political and economic organization of the country. I fully recognize the practical and social relevance of VALS as a simple, fast and effective means for communications with both authorities and societies at risk, in those many countries where relatively small volcano observatories are engaged in daily efforts to raise awareness of volcanic risks and promote hazard education; those colleagues should be admired and encouraged to maintain the methods and languages they feel most fruitful and appropriate for the specific conditions under which they act. The target for the arguments in this paper is, rather, Naples and its suburbs lying within, above and around the three active, potentially destructive volcanoes Vesuvius, Campi Flegrei and Ischia; Auckland, New Zealand, within the Auckland Volcanic Field; Seattle, Washington State, US, menaced by lahars from Mount Rainier; Shimabara, in Japan, under the threat of tsunamis generated by the activity of Mount Unzen; and many other such situations involving large cities and infrastructures, not excluding cities in lessdeveloped countries, such as Arequipa (Peru) close to El Misti volcano, Pasto (Colombia) close to Galeras, Managua (Nicaragua) close to Masaya, Quito (Ecuador) surrounded by Guagua Pichincha to the West, Pululahua to the North, and other volcanoes including Cotopaxi far to the South, still menacing for lahars; and many others. In all such situations the level of risk calls for adequate procedures based on a rational approach, in which varied expertise is harnessed in a coordinated effort, uncertainties are fully recognised and quantified, communications are unambiguous, and responsibilities reflect the social role and societal mandate of all groups involved. In turn, such requirements call for a deep reconsideration of present alert level systems. Current systems, as discussed throughout this paper, do not achieve the desired outcome.

A final note regards the use of alert levels in communications with VAACs. These centres have been created by ICAO, the International Civil Aviation Organization, to "keep aviators informed of volcanic hazards" (http:// www.ssd.noaa.gov/VAAC/vaac.html). I stress here the peculiarities of a system that requires fast information flow as well as standardized, simple communication, and most importantly, that does not imply the establishment of complex decision-making procedures comparable to those necessary for urban areas as depicted above. The conditions under which decisions are made by pilots and their ground control centres are exemplified in statements related to the establishment of VAAC centers: "the only way to ensure that there would be no loss of an aircraft was to alert pilots in a timely manner to divert their flight around the cloud" (https://en.wikipedia.org/wiki/Volcanic_Ash_Advisory_Center); "civilian aviation authorities and the airline industry actively strive to avoid any aircraft encounter with airborne ash" (http://www.wovo.org/aviation-colourcodes.html). In other words, in principle, the possible, likely, or established presence of a volcanic ash cloud should equally trigger the decision to divert the airplane route in order to avoid the ash - and that's it. Through the lens of a cost/benefit analysis, that is a situation where the cost of the mitigating action (route diversion) is incomparably lower than the possible losses associated with no action; therefore, a very small probability is sufficient to fully justify the decision to act. Similar situations are encountered on the ground where relatively few people and non-critical infrastructures are exposed to risk by a reawakening volcano. In such conditions there is no real need to establish complex decision-making procedures, since the costs for full preventive evacuation are negligible compared to potential losses in terms of human lives, and decisions can be made with little warning (i.e., with small eruption probability). In all such cases the costs associated with developing rational decision-making procedures as depicted in this paper may not be justified in terms of potential losses in the capability to efficiently deal with the risk. This is another example of cost/benefit arguments, this time applied to procedures rather than actions. The use of simple volcanic alert level systems, although in principle "irrational" as compared to "rational" as defined throughout this paper, may thus be effective and justified for the purpose of diverting aircrafts as well as for managing low-risk volcanic crises.

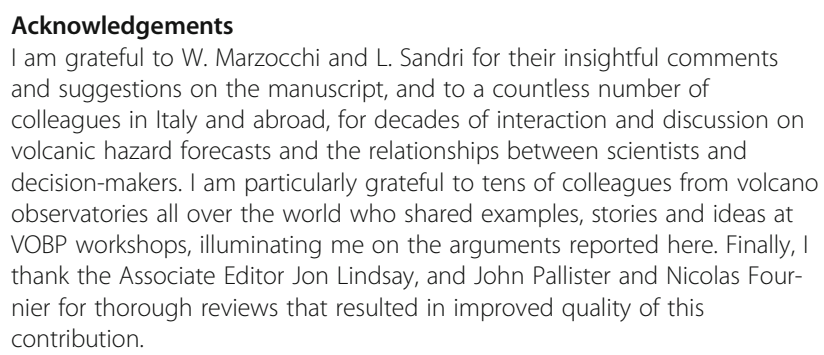

Availability of data and materials

Alert levels of current use at observatories worldwide, considered in this manuscript, are available in quoted papers or in observatory websites. Calculations in Fig. 1 are reported with the consent of the author of the calculations (quoted in the caption). 


\section{Author's Information}

This article derives from $15+$ years of experience by the author in coordinating and managing activities and projects aimed at volcanic hazard forecasts, and in contributing to structure volcano surveillance activities in Italy as well as the relationships between volcano scientists and Civil Protection authorities.

\section{Ethics approval and consent to participate}

Not applicable.

\section{Consent for publication}

Not applicable.

\section{Competing interests}

The author declares that he has no competing interests.

\section{Publisher's Note}

Springer Nature remains neutral with regard to jurisdictional claims in published maps and institutional affiliations.

\section{Received: 15 February 2017 Accepted: 11 July 2017}

Published online: 31 August 2017

\section{References}

Anderson K, Segall P. Bayesian inversion of data from effusive volcanic eruptions using physics-based models: application to Mount St. Helens 2004-2008. J Geophys Res. 2013;118:2017-37.

Aspinall WP, Woo G, Voight B, Baxter PJ. Evidence-based volcanology: application to eruption crises. J Volcanol Geotherm Res. 2003;128:273-85.

Aspinall WP, Carniel R, Jaquet O, Woo G, Hincks T. Using hidden muslti-state Markov models with multi-parameter volcanic data to provide empirical evidence for alert level decision-support. J Volcanol Geotherm Res. 2006;153: 112-124.

Aspinall WP, Woo G. Santorini unrest 2011-2012: an immediate Bayesian belief network analysis of eruption scenario probabilities for urgent decision support under uncertainty. J Appl Volcanol. 2014;3:12.

Bartolini S, Geyer A, Marti J, Pedrazzi D, Aguirre-Diaz G. Volcanic hazard on Deception Island (south Shetland Islands, Antarctica). J Volcanol Geotherm Res. 2014;285:150-68.

Bartolini S, Sobradelo R, Marti J. ST-HASSET for volcanic hazard: a python tool for evaluating the evolution of unrest indicators. Comput Geosci. 2016;93:77-87.

Baxter PJ, Aspinall WP, Neri A, Zuccaro G, Spence RJS, Cioni R, Woo G. Emergency planning and mitigation at Vesuvius: a new evidence-based approach. J Volcanol Geotherm Res. 2008;178:454-73.

Bebbington MS. Long-term forecasting of volcanic explosivity. Geophys J Int. 2014:197:1500-15.

Bebbington M, Zitikis R. Dynamic uncertainty in cost-benefit analysis of evacuation prior to a volcanic eruption. Math Geosci. 2016;48:123-48.

Becerril L, Bartolini S, Sobradelo R, Marti J, Morales JM, Galindo I. Long-term volcanic hazard assessment on el Hieroo (Canary Islands). Nat Hazards Earth Syst Sci. 2014;14:1853-70.

Bell AF, Kilburn CRJ. Precursors to dyke-fed eruptions at basaltic volcanoes: insights from patterns of volcano-tectonic seismicity at Kilauea volcano, Hawaii. Bull Volcanol. 2012;74:325-39.

Bevilacqua A, Isaia R, Neri A, et al. Quantifying volcanic hazard at Campi Flegrei caldera (Italy) with uncertainty assessment: 1. Vent opening maps J Geophys Res Solid Earth. 2015;120:2309-29.

Boue A, Lesage P, Cortés G, Valette B, Reyes-Dàvila G. Real-time eruption forecasting using the material failure forecast method with a Bayesian approach. J Geophys Res Solid Earth. 2015;120:2143-61.

Brancato A, Gresta S, Alparone S, et al. Application of BET_EF at Mount Etna: a retrospective analysis (years 2001-2005). Ann Geophys. 2011;54:642-61.

Brancato A, Gresta S, Sandri L, et al. Quantifying probabilities of eruption at a well-monitored active volcano: an application to Mt. Etna (Sicily, Italy). Boll Geofisica Teorica e Applicata. 2012;53:55-74.

Bretton RJ, Gottsmann J, Aspinall WP, Christie R. Implications of legal scrutiny processes (including the L'Aquila trial and other recent court cases) for future volcanic risk governance. J Appl Volcanol. 2015:4:18.

Cartlidge E. Quake experts to be tried for manslaughter. Science. 2011;332:1135-6.

Fearnley CJ. Assigning a volcano alert level: negotiating uncertainty, risk, and complexity in decision-making processes. Environ Plan A. 2013;45:1891-911.
Fearnley CJ, McGuire WJ, Davies G, Twigg J. Standardisation of the USGS volcano alert level system (VALS): analysis and ramifications. Bull Volcanol. 2012;74: 2023-36.

Garcia-Aristizabal A, Selva J, Fujita E. Integration of stochastic models for longterm eruption forecasting into a Bayesian event tree scheme: a basis method to estimate the probability of volcanic unrest. Bull Volcanol. 2013;75:689.

Heltz RT. Crystallization history of Kilauea Iki lava lake as seen in drill cores recovered in 1967-1979. Bull Volcanol. 1980;43:675-701.

Heltz RT. Differentiation behaviour of Kilauea Iki lava lake, Kilauea volcano, Hawaii: an overview of past and current work. In: Mysen BO, editor. Magmatic processes: physicochemical principles. Geochem Soc spec pub: University Park, PA; 1987.

Jordan TH, Chen Y-T, Gasparini P et al. (2011) Operational earthquake forecasting. State of knowledge and guidelines for utilization. Ann Geophys 54: 4. 315-391.

Jordan TH, Marzocchi W, Michael AJ, Gerstenberger MC. Operational earthquake forecasting can enhance earthquake preparedness. Seismol Res Lett. 2014;85:955-9.

Kahneman D (2011) Thinking, fast and slow. Farrar, Straus and Giroux, New York. 978-0374275631, 499 pages.

Lau RR, Redlawsk DP. Advantages and disadvantages of cognitive heuristics in political decision making. Am J Political Sci. 2001;45:951-71.

Levy H. Stochastic dominance: investment decision making under uncertainty: Springer; 2015

Lindsay J, Marzocchi W, Jolly G, Constantinescu R, Selva J, Sandri L. Towards realtime eruption forecasting in the Auckland volcanic field: application of BET_ EF during the new Zealand National Disaster Exercise 'Ruaumoko'. Bull Volcanol. 2010;72:185-204.

Lipshitz R, Strauss O. Coping with uncertainty: a naturalistic decision-making analysis. Organ Behav Hum Decis Processes. 1997;69:149-63.

Martin AJ, Umeda K, Connor CB, Weller JN, Zhao D, Takahashi M. Modeling longterm volcanic hazards through Bayesian inference: an example from the Tohoku volcanic arc. Japan J Geophys Res. 2004;109 doi:10.1029/2004JB003201.

Marzocchi W, Sandri L, Gasparini P, Newhall C, Boschi E. Quantifying probabilities of volcanic events: the example of volcanic hazard at mount Vesuvius. J Geophys Res. 2004;109 doi:10.1029/2004JB003155.

Marzocchi W, Woo G. Probabilistic eruption forecasting and the call for an evacuation. Geophys Res Lett. 2007;34 doi:10.1029/2007GL031922.

Marzocchi W, Woo G. Principles of volcanic risk metrics: theory and the case study of mount Vesuvius and Campi Flegrei. Italy J Geophys Res Solid Earth. 2009;114 doi:10.1029/2008JB005908

Marzocchi W, Sandri L, Selva J. BET_EF: a probabilistic tool for long- and shortterm eruption forecasting. Bull Volcanol. 2008;70:623-32.

Marzocchi W, Sandri L, Selva J. BET_VH: a probabilistic tool for long term volcanic hazard assessment. Bull Volcanol. 2010;72:705-16.

Marzocchi W, Bebbington MS. Probabilistic eruption forecasting at short and long time scales. Bull Volcanol. 2012;74:1777-805.

Marzocchi W, Newhall C, Woo G. The scientific management of volcanic crises. J Volcanol Geotherm Res. 2012;247:181-9.

Marzocchi W, Jordan TH. Operational earthquake forecasting can enhance earthquake preparedness. Seismol Res Lett. 2014:85:955-9.

Neri A, Aspinall WP, Cioni R, et al. Developing an event tree for probabilistic hazard and risk assessment at Vesuvius. J Volcanol Geotherm Res. 2008;178:397-415.

Nosengo N. Scientists on trial over L'Aquila deaths. Nature. 2011;474:15.

Newhall CG, Hoblitt R. Constructing event trees for volcanic crises. Bull Volcanol. 2002;64:3-20.

Newhall CG, Pallister JS. Using multiple data sets to populate probabilistic volcanic event trees. In: Papale P, editor. Volcanic hazards, risks, and disasters. Amsterdam: Elsevier; 2015.

Oliveros AQ, Carniel R, Tarraga M, Aspinall W. On the application of hidden Markov model and Bayesian belief network to seismic noise at Las Cañadas caldera, Tenerife, Spain. Chaos, Solitons Fractals. 2008;37:849-57.

Orsi G, Di Vito MA, Selva J, Marzocchi W. Long-term forecast of eruption style and size at Campi Flegrei caldera (Italy). Earth Planet Sci Lett. 2009;287:265-76.

Pàlsson B, Hólmgeirsson S, Guðrmundsson Á, Bóasson HÁ, Ingason K, Sverrison H, Thórhalsson S. Drilling of the well IDDP-1. Geothermics. 2014;49:23-30.

Papale P, De Natale G and the INGV 'Campi Flegrei response team' (2014) Observatory response to a volcanic crisis: the Campi Flegrei simulation exercise. Paper presented at the Cities on Volcanoes 8 Conference Yogyakarta, Indonesia, 9-13 September 2014.

Passarelli L, Sansò B, Sandri L, Marzocchi W. Testing forecasts of a new Bayesian time-predictable model of eruption occurrence. J Volcanol Geotherm Res. 2010a;198:57-75. 
Passarelli L, Sandri L, Bonazzi A, Marzocchi W. Bayesian hierarchical time predictable model for eruption occurrence: an application to Kilauea volcano. Geophys J Int. 2010b;181:1525-38.

Potter SH, Jolly GE, Neall VE, Johnston DM, Scott BJ. Communicating the status of volcanic activity: revising New Zealand's volcanic alert level system. J Appl Volcanol. 2014;3:13.

Potter SH, Scott BJ, Jolly GE, Neall VE, Johnston DM. Introducing the volcanic unrest index (VUI): a tool to quantify and communicate the intensity of volcanic unrest. Bull Volcanol. 2015;77:77.

Rouwet D, Sandri L, Marzocchi W, Gottsmann J, Selva J, Tonini R, Papale P. Recognizing and tracking volcanic hazards related to non-magmatic unrest: a review. J Appl Volcanol. 2014;3:17.

Sandri L, Guidoboni E, Marzocchi W, Selva J. Bayesian event tree for eruption forecasting (BET_EF) at Vesuvius, Italy: a retrospective forward application to the 1631 eruption. Bull Volcanol. 2009:71:729-45.

Sandri L, Jolly G, Lindsay J, Howe T, Marzocchi W. Combining long- and shortterm probabilistic volcanic hazard assessment with cost-benefit analysis to support decision making in a volcanic crisis from the Aucland volcanic field, New Zealand. Bull Volcanol. 2012;74:705-23.

Sandri L, Thouret J-C, Caonstantinescu R, Biass S, Tonini R. Long-term multihazard assessment for el Misti volcano (Peru). Bull Volcanol. 2014;76:771.

Sandri L, Costa A, Selva J, Tonini R, Macedonio G, Folch A, Suplizio R. Beyond eruptive scenarios: assessing tephra fallout hazard from Neapolitan volcanoes. Sci Rep. 2016;6 doi:10.1038/srep24271.

Selva J, Marzocchi W, Papale P, Sandri L. Operational eruption forecasting at highrisk volcanoes: the case of Campi Flegrei, Naples. J Appl Volcanol. 2012;1:5.

Selva J, Costa A, Sandri L, Macedonio G, Marzocchi W. Probabilistic short-term volcanic hazard in phases of unrest: a case study for tephra fallout. J Geophys Res Solid Earth. 2014;119:8805-26.

Selva J, Marzocchi W, Sandri L, Costa A. Operational short-term volcanic hazard analysis: methods and perspectives. In: Papale P, editor. Volcanic hazards, risks, and disasters. Amsterdam: Elsevier; 2015.

Sheldrake T. Long-term forecasting of eruption hazards: a hierarchical approach to merge analogous eruptive histories. J Volcanol Geotherm Res. 2014;286:15-23.

Sobradelo R, Marti J. Bayesian event tree for long-term volcani hazard assessment: application to Teide-Pico Viejo stratovolcanoes, Tenerife. Canary Islands J Geophys Res Solid Earth. 2010:115 doi:10.1029/2009JB006566.

Sobradelo R, Marti J, Kilburn C, López C. Probabilistic approach to decisionmaking under uncertainty during volcanic crises: retrospective application to the el Hierro (Spain) 2011 volcanic crisis. Nat Hazards. 2015;76:979-98.

Thompson MA, Lindsay J, Sandri L, Biass S, Bonadonna C, Jolly G, Marzocchi W. Exploring the influence of vent location and eruption style on tephra fall hazard from the Okataina volcanic Centre, New Zealand. Bull Volcanol. 2015;77:38.

Tonini R, Sandri L, Thompson MA. PyBetVH: a python tool for probabilistic volcanic hazard assessment and for generation of Bayesian hazard curves and maps. Comput Geosci. 2015;79:38-46.

Tonini R, Sandri L, Rouwet D, Caudron C, Marzocchi W, Suparajan. A new Bayesian event tree tool to track and quantify volcanic unrest and its application to Kawah ljen volcano. Geochem Geophys Geosyst. 2016;17:2539-55.

Winson AEG, Costa F, Newhall CG, Woo G. An analysis of the issuance of volcanic alert levels during volcanic crises. J Appl Volcanol. 2014;3:14.

\section{Submit your manuscript to a SpringerOpen ${ }^{\circ}$ journal and benefit from:}

- Convenient online submission

- Rigorous peer review

- Open access: articles freely available online

- High visibility within the field

- Retaining the copyright to your article

Submit your next manuscript at $\gg$ springeropen.com 